\title{
Approximations of Stochastic Nets by Mean of Continuous Petri Nets
}

\author{
Nabil El Akchioui \\ FST Al Hoceima, \\ University of Mohamed Premier \\ Ajdir, Al Hoceima \\ Morocco
}

\author{
Souâd Choukrad \\ FST Al Hoceima, \\ University of Mohamed Premier \\ Ajdir, Al Hoceima \\ Morocco
}

\begin{abstract}
Reliability analysis is often based on stochastic discrete event models like Markov models or stochastic Petri nets. For complex dynamical systems with numerous components, analytical expressions of the steady state are tedious to work out because of the combinatory explosion with discrete models. The contribution of this paper is to approximate the steady state of mono T-semiflow stochastic nets by mean of continuous Petri nets according to a modification of the maximal firing speed vector definition. This result is then used to accelerate convergence of stochastic simulations.
\end{abstract}

\section{Keywords}

Stochastic Petri nets, continuous Petri nets, steady state, reliability analysis.

\section{INTRODUCTION}

Reliability analysis is a major challenge to improve the safety of industrial processes. For complex dynamical systems with numerous interdependent components, such studies are mainly based on stochastic discrete event models like Markov models or Stochastic Petri Nets (SPN) [1], [2]. Such models are mathematically well founded and can be investigated in order to work out either analytical or numerical simulations. In case of large systems both studies become tedious particularly when rare events (i.e. with weak occurrence probability) are considered. The aim of this paper is to approximate the steady state of SPN or Markov models by mean of Continuous Petri Nets (CPN). The fluidification of discrete Petri nets has been recently investigated mainly for performance evaluation and control applications [3], [4], [5]. It is well known that fluidification leads to some unexpected results and numerous structural and behavioural properties are not preserved with fluidification. In general case, the steady state of a SPN cannot be approximated by the asymptotic behaviour of the corresponding continuous Petri net. The contribution of this paper is to show that, for a specific class of Petri nets (mono T-semiflow nets), and according to a modification of the maximal firing speeds, a proportionality relationship exists between both behaviours. This property is then used to accelerate convergence of stochastic simulations. SPN and $\mathrm{CPN}$ are combined for that purpose: stochastic simulation is worked out during a short time window of duration T. Then, the estimated values of stochastic average throughputs and mean markings are used to define the maximal firing speed vector of CPN. The asymptotic behaviour of CPN is shown to give an improved approximation of the stochastic steady state. The paper has five sections. Section two introduces SPN and CPN. Section three is about the analytic solution of steady state for SPN. Section four introduces the fluidification of PN and the problem is also stated. The fluidification of mono Tsemiflow SPN is discussed. Convergence acceleration and firing speed adaptation are investigated.

\section{STOCHASTIC AND CONTINUOUS PETRI NETS}

\subsection{Petri nets}

A Petri net $(\mathrm{PN})$ is defined as $<\mathrm{P}, \mathrm{T}, \mathrm{W}_{\mathrm{PR}}, \mathrm{W}_{\mathrm{PO}}>$ where $\mathrm{P}=\left\{\mathrm{p}_{1}\right.$ $\left.\mathrm{p}_{2}, \ldots, \mathrm{p}_{\mathrm{i}}\right\}$ is a finite set of $\mathrm{n}$ places and $\mathrm{T}=\left\{\mathrm{T}_{\mathrm{j}}\right\}$ is a not empty finite set of $\mathrm{q}$ transitions and $\mathrm{P} \cap \mathrm{T}=\varnothing[6] . \mathrm{W}_{\mathrm{PR}}=\left(\mathrm{w}^{\mathrm{PR}}{ }_{\mathrm{ij}}\right)$ $\in\left(\mathrm{Z}^{+}\right)^{\mathrm{n} \times \mathrm{q}}$ is the pre-incidence matrix $\left(\mathrm{w}^{\mathrm{PR}}{ }_{\mathrm{ij}}\right.$ is the weight of arc from place $\mathrm{P}_{\mathrm{i}}$ to transition $\left.\mathrm{T}_{\mathrm{j}}\right)$ and $\mathrm{W}_{\mathrm{PO}}=\left(\mathrm{w}^{\mathrm{PO}}{ }_{\mathrm{ij}}\right) \in\left(\mathrm{Z}^{+}\right)^{\mathrm{n} \times \mathrm{q}}$ is the post-incidence one ( $\mathrm{w}^{\mathrm{PO}}{ }_{\mathrm{ij}}$ is the weight of arc from transition $\mathrm{T}_{\mathrm{j}}$ to place $\mathrm{P}_{\mathrm{i}}$ ) [3]. The $\mathrm{PN}$ incidence matrix $\mathrm{W}$ is defined as $\mathrm{W}=\mathrm{W}_{\mathrm{PO}}-\mathrm{W}_{\mathrm{PR}} \in(\mathrm{Z})^{\mathrm{n} \times \mathrm{q}}$. The $\mathrm{PN}$ marking $\mathrm{M}$ is an application from the set of places $P$ to the set of non negative integer numbers $\mathrm{Z}^{+}$such that, for each place $\mathrm{P}_{\mathrm{i}} \in \mathrm{P}, \mathrm{m}_{\mathrm{i}}=\mathrm{M}\left(\mathrm{P}_{\mathrm{i}}\right)$ is the number of tokens in place $\mathrm{P}_{\mathrm{i}} \cdot \mathrm{M}_{\mathrm{I}}$ is the $\mathrm{PN}$ initial marking.

Right and left natural annullers of the token flow matrix $\mathrm{W}$ are called T- and P-semi flows, respectively. When $\mathrm{Y}^{\mathrm{T}} \cdot \mathrm{W}=0$. the net is said to be conservative and When W.x $=0$. The net is said to be consistent.Ina consistent net, a vector $\mathrm{x}$ such that $\mathrm{W} . \mathrm{x}=0$ represents a repetitive sequence, or in other words, a potential steady-state behaviour of the system in which all transitions are fired [7].

\subsection{Stochastic Petri Nets(SPN)}

A Stochastic PN (SPN) is defined by a timed PN whose transitions firing periods are characterized by random distributions according to an exponential distribution of varying parameter round $\left(\mathrm{n}_{\mathrm{j}}(\mathrm{M})\right) \cdot \mu_{\mathrm{j}}$. This model has been introduced by Molloy [8], and several extensions have been developed [1]; [9] for the reliability analysis of reparable systems. A SPN, $\langle\mathrm{PN}, \mu\rangle$, is a PN associated with a firing rate vector $\mu=\left(\mu_{j}\right) \in\left(R^{+}\right)^{\mathrm{q}}$. SPN Each transitions $T_{j}$ is characterized by the firing rate $\mu_{\mathrm{j}}$ so that $\mu_{\mathrm{j}} \mathrm{dt}$ is the probability that the transition $T_{j}$ will fire between $t$ and $t+d t$ when the transition $T_{j}$ has been enabled, with degree 1 at $t$. The marking process of a SPN will be characterized according to the PN incidence matrices, the initial marking, the firing rates, the firing policy, the server policy and the execution policy [10], [9]. SPN that are considered in this paper satisfy the following assumptions:

(H1) the firing policy is a race policy: the transition whose firing time elapses first is assumed to be the one that will fire next.

(H2) the server policy is of type infinite server: the minimal period of each transition $T_{j}$ is defined with a stochastic duration which is characterized according to an exponential distribution of varying parameter $\operatorname{round}\left(\mathrm{n}_{\mathrm{j}}(\mathrm{M})\right) . \mu_{\mathrm{j}}$. The function $n_{j}(M)$ is the enabling degree of transition $T_{j}$ for marking $\mathrm{M}$ : 


$$
\mathrm{n}_{\mathrm{j}}(\mathrm{M})=\min \left(\mathrm{m}_{\mathrm{i}} / \mathrm{w}^{\mathrm{PR}}{ }_{\mathrm{ij}}\right) \text { for all } \mathrm{P}_{\mathrm{i}} \in{ }^{\circ} \mathrm{T}_{\mathrm{j}}(1)
$$

where ${ }^{\circ} \mathrm{T}_{\mathrm{j}}$ stands for the set of $\mathrm{T}_{\mathrm{j}}$ upstream places and "round (.)" is the integer part of (.).

(H3) the execution policy is of type « resampling memory »: at the entrance in a marking, the remaining firing time of all transitions that were enabled is reset.

\subsection{Continuous Petri Nets(CPN)}

Continuous Petri Nets (CPN) have been developed in order to provide a continuous approximation of the discrete behaviours of discrete PN [3]; [5]. A CPN is defined as < PN, $\mathrm{X}_{\max }>$ where PN is a Petri nets and $X_{\max }=\left(x_{\max }\right) \in\left(\mathbf{R}^{+}\right)^{\mathrm{q}}$ is the vector of maximal firing speeds. The marking $\mathrm{m}_{\mathrm{i}}(\mathrm{t}) \in \mathbf{R}^{+}$of each place $P_{i}$ is a non-negative real valued function of time and each transition firing is a flow of marks in continuous PN. $\mathrm{X}(\mathrm{t})=\left(\mathrm{x}_{\mathrm{j}}(\mathrm{t})\right) \in\left(\mathbf{R}^{+}\right)^{\mathrm{q}}$ is the firing speeds vector at time $\mathrm{t}$. The marking evolution is given by (2):

$$
\mathrm{dM}(\mathrm{t}) / \mathrm{dt}=\mathrm{W} \cdot \mathrm{X}(\mathrm{t})
$$

Finite server (i.e. constant speeds) and infinite server (i.e. variable speeds) semantics exist for CPN. In this paper only the infinite server semantic is considered: $X(t)$ depends continuously on the marking of the places according to (3):

$$
x_{j}(t)=x_{\max } \cdot n_{j}(M)
$$

\section{STEADY STATES OF SPN}

For live SPN that satisfy hypotheses $(\mathrm{H} 1)$ to $(\mathrm{H} 3)$ and with a finite number of states in the reachability graph, the marking process is mapped into a Markov model with state space isomorphic to the reachability graph of the SPN model [10]; [8]; [11] In that case the steady state of SPN can be worked out according to the steady state probabilities of the Markov model.

Let define $\mathrm{X}_{\text {ats }}=\left(\mathrm{x}_{\text {ats }} \mathrm{j}\right) \in\left(\mathbf{R}^{+}\right)^{\mathrm{q}}$ as the average throughputs vector and $\mathrm{M}_{\mathrm{mms}}=\left(\mathrm{m}_{\mathrm{mms}}\right) \in\left(\mathbf{R}^{+}\right)^{\mathrm{n}}$ as the mean markings vector of SPN and $\Pi_{\mathrm{ss}}=\left(\pi_{\mathrm{ss} \mathrm{k}}\right) \in[0,1]^{1 \times \mathrm{N}}$ as the steady state probabilities vector of the associated Markov model with $\mathrm{N}$ states. Let us also define $\mathrm{A}(\mu) \in(\mathbf{R})^{\mathrm{N} \times \mathrm{N}}$ as the transition matrix of the Markov model (obtained according to the reachability graph $\mathrm{R}\left(\mathrm{PN}, \mathrm{M}_{\mathrm{I}}\right)$ of $\mathrm{SPN}$ and to the firing rate vector $\mu)$ and $1_{\mathrm{N}}=(1, \ldots, 1)^{\mathrm{T}} \in\left(\mathbf{R}^{+}\right)^{\mathrm{N}}$ as the column vector of size $\mathrm{N}$ with all entries equal to 1 . It is well known that $\Pi_{\mathrm{ss}}$ is the single solution of equations (4) [12], [13]:

$$
\begin{aligned}
& \Pi_{\mathrm{ss}} \cdot \mathrm{A}(\mu)=0 \\
& \Pi_{\mathrm{ss}} \cdot 1_{\mathrm{N}}=1
\end{aligned}
$$

As a consequence, $X_{\text {ats }}$ and $\mathrm{M}_{\mathrm{mms}}$ are obtained according to equations (5) and (6):

$$
\begin{aligned}
& x_{a t s j}=\mu_{j} \cdot\left(\sum_{k=1 \ldots N} n_{j}\left(M_{k}\right) \cdot \pi_{s s k}\right) \\
& m_{m m s i}=\sum_{k=1 \ldots N} m_{k i} \cdot \pi_{s s k}
\end{aligned}
$$

where $\mathrm{M}_{\mathrm{k}}=\left(\mathrm{m}_{\mathrm{k}} \mathrm{i}\right) \in\left(\mathbf{R}^{+}\right)^{\mathrm{n}}$ stands for the marking vector corresponding to the state $\mathrm{k}$ of the Markov model.

This method gives an analytical solution of the SPN steady state in case of ergodic Markov models, but requires the computation of the transition matrix $\mathrm{A}(\mu)$ and as a consequence the reachability graph $\mathrm{R}\left(\mathrm{PN}, \mathrm{M}_{\mathrm{I}}\right)$ of the SPN. For large systems, the computational time and memory requirements necessary to work out $\mathrm{R}\left(\mathrm{PN}, \mathrm{M}_{\mathrm{I}}\right)$ become important as long as the number $\mathrm{N}$ of states increases exponentially. In that sense, SPN can be considered as a stochastic estimator for the Markov model. The advantage of this estimator is that the determination of $\mathrm{R}\left(\mathrm{PN}, \mathrm{M}_{\mathrm{I}}\right)$ is no longer required, the drawback is the slow convergence of the stochastic estimator, particularly in case of rare events.

The example of a simple manufacturing system (Fig. 1) with 5 machines (i.e. $\mathrm{T}_{1}$ to $\mathrm{T}_{5}$ ), 3 tools with limited resources (i.e. $\mathrm{P}_{1}$ to $\mathrm{P}_{3}$ ) and 2 buffers with limited capacities (i.e. $\left\{\mathrm{P}_{4}, \mathrm{P}_{5}\right\}$ and $\left.\left\{\mathrm{P}_{6}, \mathrm{P}_{7}\right\}\right)$ illustrates this difficulty. The $\mathrm{PN}$ model of this system has 1 T-semiflow $\mathrm{x}=\left(\begin{array}{lllll}2 & 2 & 2 & 2 & 1\end{array}\right)^{\mathrm{T}}$ and 5 P-semiflows

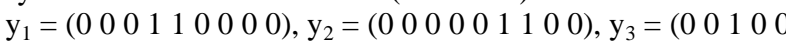

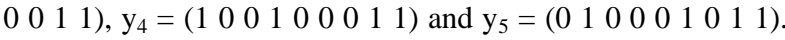
As a consequence only the flow of transition $\mathrm{T}_{5}$ and the marking of places $\mathrm{P}_{1}, \mathrm{P}_{2}, \mathrm{P}_{8}$ and $\mathrm{P}_{9}$ will be considered. Other flows and markings are given by (7):

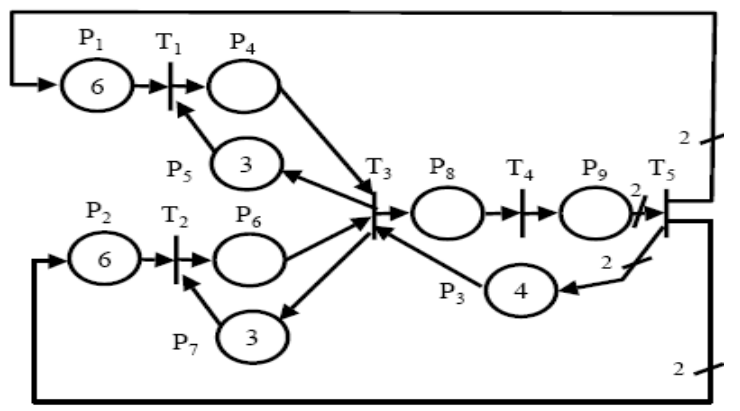

Fig. 1. A simple manufacturing system with firing rate

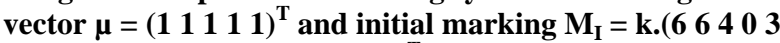
$0300)^{\mathrm{T}}$ [5].

$$
\begin{aligned}
& \mathrm{x}_{1}=\mathrm{x}_{2}=\mathrm{x}_{3}=\mathrm{x}_{4}=2 \cdot \mathrm{x}_{5} \\
& \mathrm{~m}_{4}=\mathrm{y}_{4} \cdot \mathrm{M}_{\mathrm{I}}-\mathrm{m}_{1}-\mathrm{m}_{8}-\mathrm{m}_{9} \\
& \mathrm{~m}_{6}=\mathrm{y}_{5} \cdot \mathrm{M}_{\mathrm{I}}-\mathrm{m}_{2}-\mathrm{m}_{8}-\mathrm{m}_{9} \\
& \mathrm{~m}_{3}=\mathrm{y}_{3} \cdot \mathrm{M}_{\mathrm{I}}-\mathrm{m}_{8}-\mathrm{m}_{9} \\
& \mathrm{~m}_{5}=\mathrm{y}_{1} \cdot \mathrm{M}_{\mathrm{I}}-\mathrm{y}_{4} \cdot \mathrm{M}_{\mathrm{I}}+\mathrm{m}_{1}+\mathrm{m}_{8}+\mathrm{m}_{9} \\
& \mathrm{~m}_{7}=\mathrm{y}_{2} \cdot \mathrm{M}_{\mathrm{I}}-\mathrm{y}_{5} \cdot \mathrm{M}_{\mathrm{I}}+\mathrm{m}_{2}+\mathrm{m}_{8}+\mathrm{m}_{9}
\end{aligned}
$$

Equations (7) hold for SPN and CPN. Steady state markings and flows are reported in Table I with respect to initial marking.

Table 1. Number of states, average throughputs and mean markings of SPN from fig. 1 in function of $k$

\begin{tabular}{|c|c|c|c|c|c|c|}
\hline $\mathbf{K}$ & $\mathbf{N}$ & $\mathbf{x}_{\text {ats }}$ & $\mathbf{m}_{\text {ats1 }}$ & $\mathbf{m}_{\text {ats2 }}$ & $\mathbf{m}_{\text {ats8 }}$ & $\mathbf{m}_{\text {ats9 }}$ \\
\hline 1 & 205 & 0.50 & 1.75 & 1.75 & 1.00 & 1.48 \\
\hline 2 & 1885 & 1.13 & 3.51 & 3.51 & 2.25 & 2.75 \\
\hline 3 & 7796 & 1.77 & 5.20 & 5.21 & 3.54 & 4.07 \\
\hline 4 & 22187 & 2.42 & 6.97 & 6.91 & 4.84 & 5.36 \\
\hline$\ldots$ & $\ldots$ & $\ldots$ & $\ldots$ & $\ldots$ & $\ldots$ & $\ldots$ \\
\hline$\infty$ & $\infty$ & $\infty$ & $\infty$ & $\infty$ & $\infty$ & $\infty$ \\
\hline
\end{tabular}

\section{FLUIDIFICATION OF SPN \\ 4.1. Fluidification of $P N$}

The steady state of a SPN $=\langle\mathrm{PN}, \mu\rangle$ and the one resulting of a $\mathrm{CPN}=<\mathrm{PN}, \mathrm{X}_{\max }>$ with same structure, initial marking and $X_{\max }=\mu$ are in general case not identical. For example, the steady state of the PN in Fig. 1 considered as continuous is given in Table II. It can also be noticed that the difference between SPN and CPN steady state decreases with respect to 
the marking. More generally, a PN can be live as discrete and non-live as continuous. In a similar way, a discrete bounded system may be unbounded as continuous [17]; [5]. Moreover, like in discrete nets, the throughput of a CPN does not fulfil in general any monotonicity property, neither with respect to the initial marking, nor with respect to the structure of the net, nor with respect to the transitions rates. [4]. The throughput of a $\mathrm{CPN}$ is not in general an upper bound of the throughput of the discrete PN [4].

Table 2. Average throughputs and mean markings of CPN from fig. 1 in function of $k$

\begin{tabular}{|c|c|c|c|c|c|}
\hline $\boldsymbol{K}$ & $\mathbf{x}_{\text {atc } 5}$ & $\boldsymbol{m}_{\text {atc } \mathbf{~}}$ & $\boldsymbol{m}_{\text {atc } \mathbf{2}}$ & $\boldsymbol{m}_{\text {atc } \boldsymbol{~}}$ & $\boldsymbol{m}_{\text {atc } \boldsymbol{~}}$ \\
\hline 1 & 0.67 & 1.67 & 1.67 & 1.33 & 1.33 \\
\hline 2 & 1.33 & 3.33 & 3.33 & 2.67 & 2.67 \\
\hline 3 & 2 & 5 & 5 & 4 & 4 \\
\hline 4 & 2.67 & 6.67 & 6.67 & 5.33 & 5.33 \\
\hline$\ldots$ & $\ldots$ & $\ldots$ & $\ldots$ & $\ldots$ & $\ldots$ \\
\hline$\infty$ & $\infty$ & $\infty$ & $\infty$ & $\infty$ & $\infty$ \\
\hline
\end{tabular}

Some results exist to find upper bounds of the steady state for CPN and also for discrete PN according to the resolution of linear programming problems [2];[5]. But no comparison exists between both upper bounds (discrete and continuous ones). Another promising solution is to consider subclasses of PN structures. Mono T-Semiflows nets (MTS) are of particular interest as long as MTS are conservative and have a single minimal T-semiflows $\mathrm{x} \in\left(\mathbf{Z}^{+}\right)^{\mathrm{q}}$ (i.e. W.x $=0$; the set of non zero entries of $\mathrm{x}$ is not a proper superset of the support of any other semiflow and the g.c.d of $x$ entries is 1) whose support contains all the transition $(x>0)$. As a consequence, for MTS, the flow in the steady state is proportional to $\mathrm{x}$ and an analytical expression of the asymptotic flow $X_{\text {atc }}$ can be stated according to the CPN structure and maximal firing speed vector [4]. For neutral strongly connected state graphs $\mathrm{CPN}$, average throughputs and mean marking are also obtained according to the study of elementary circuits and $\mathrm{T}-$ coverture of the net [13], [15], [18]. At last, let us notice the discussion according to a local approximation of the SPN [16], [12], [11]; [17] for join - free SPN and CPN.

\subsection{Problem statement}

The aim of this section is to provide some theoretical and numerical tools to approximate the steady state of a given SPN using the asymptotic behaviour of a CPN. When the structure, initial marking and transition rate are fixed, the steady states of SPN and CPN are generally not identical. The problem will be relaxed regarding the definition of the maximal firing speed of $\mathrm{CPN}$ and we study if the mean markings and average throughputs of a given $\mathrm{SPN}=\langle\mathrm{P}, \mathrm{T}$, $\mathrm{W}_{\mathrm{PR}}, \mathrm{W}_{\mathrm{PO}}, \mathrm{M}_{\mathrm{I}}, \mu>$ that satisfies assumptions $\mathrm{H} 1$ to $\mathrm{H} 3$ can be by the asymptotic behaviour of a $\mathrm{CPN}=<\mathrm{P}, \mathrm{T}, \mathrm{W}_{\mathrm{PR}}, \mathrm{W}_{\mathrm{PO}}, \mathrm{M}_{\mathrm{I}}$, $\mathrm{X}_{\max }>$ with infinite server semantic. Fluidification of MTS PN is considered in section VI.C. Convergence accelerator for stochastic estimator are explored in section VI.D $\left(\mathrm{X}_{\max }\right.$ is assumed to be constant) and firing speed adaptation is investigated in section VI.E $\left(\mathrm{X}_{\max }\right.$ is assumed to be function of time).

\subsection{Fluidification of MTS SPN}

Let define the average throughput vector (i.e. asymptotic firing speeds vector) $\mathrm{X}_{\text {atc }}=\left(\mathrm{x}_{\text {atc }} \mathrm{j}\right) \in\left(\mathbf{R}^{+}\right)^{\mathrm{q}}$ and the mean marking (i.e. asymptotic marking vector) $\mathbf{M}_{\mathrm{mmc}}=\left(\mathrm{m}_{\mathrm{mmc}} \mathrm{i}\right) \in$ $\left(\mathbf{R}^{+}\right)^{\mathrm{n}}$ of CPN. Similarly, $\mathrm{X}_{\text {ats }}=\left(\mathrm{x}_{\text {ats }}\right) \in\left(\mathbf{R}^{+}\right)^{\mathrm{q}}$ refers to the average throughput and $\mathrm{M}_{\mathrm{mms}}=\left(\mathrm{m}_{\mathrm{mms}}\right) \in\left(\mathbf{R}^{+}\right)^{\mathrm{n}}$ refers to the mean marking of SPN. In the following we suppose that the considered CPN and SPN have steady states (i.e. a stationary average throughput and a stationary mean marking).

Lemma 1: If a SPN (resp. CPN) has a steady state, then W. $\mathrm{X}_{\text {ats }}=0$ (resp. W. $\mathrm{X}_{\mathrm{atc}}=0$ )

Proof: If SPN has a steady state, then for each place $\mathrm{P}_{\mathrm{i}}$, the mean marking $\mathrm{m}_{\mathrm{mms}} \mathrm{i}$ is stationary and leads to:

$\sum_{j=1 \ldots q} w_{i j} \cdot x_{a t s j}=0$

As a conclusion $\mathrm{W} . \mathrm{X}_{\text {ats }}=0$. The proof is similar for CPN. A proof can also be found in [19];[20]; [17].

Let consider a $\mathrm{SPN}=\left\langle\mathrm{P}, \mathrm{T}, \mathrm{W}_{\mathrm{PR}}, \mathrm{W}_{\mathrm{PO}}, \mathrm{M}_{\mathrm{I}}, \mu\right\rangle$, define the $\mathrm{CPN}\left(\mathrm{X}_{\mathrm{ats}}, \mathrm{M}_{\mathrm{mms}}\right)=\left\langle\mathrm{P}, \mathrm{T}, \mathrm{W}_{\mathrm{PR}}, \mathrm{W}_{\mathrm{PO}}, \mathrm{M}_{\mathrm{I}}, \mathrm{X}_{\max }>\right.$ with infinite server semantic and:

$\mathrm{x}_{\max \mathrm{j}}=\mathrm{w}^{\mathrm{PR}}{ }_{\mathrm{ij}} \cdot\left(\mathrm{x}_{\text {ats }}\right) /\left(\mathrm{m}_{\mathrm{mmsi}}\right)$ where $\mathrm{P}_{\mathrm{i}}={ }^{\circ} \mathrm{T}_{\mathrm{j}}$

$\mathrm{m}_{\mathrm{mms} \mathrm{i}} / \mathrm{w}^{\mathrm{PR}}{ }_{\mathrm{ij}}=\min \left(\mathrm{m}_{\mathrm{mms} \mathrm{k}} / \mathrm{w}^{\mathrm{PR}}{ }_{\mathrm{kj}}\right)$ for all $\mathrm{P}_{\mathrm{k}} \in{ }^{\circ} \mathrm{T}_{\mathrm{j}}$

$\mathrm{CPN}\left(\mathrm{X}_{\mathrm{ats}}, \mathrm{M}_{\mathrm{mms}}\right)$ has the same structure and initial marking as SPN and the maximal firing speeds are defined according to the steady state of the SPN.

Lemma 2: The asymptotic firing speeds vector $\mathrm{X}_{\text {atc }}$ and marking vector $\mathrm{M}_{\mathrm{mmc}}$ of $\mathrm{MTS} \operatorname{CPN}\left(\mathrm{X}_{\mathrm{ats}}, \mathrm{M}_{\mathrm{mms}}\right)$ satisfy equation (10):

For all $\mathrm{T}_{\mathrm{j}}, \frac{x_{\text {atc } j}}{x_{\text {ats } j}}=\frac{m_{m m c i}}{m_{m m s i}}=\alpha$

with $\mathrm{m}_{\mathrm{mmsi}} / \mathrm{w}^{\mathrm{PR}}{ }_{\mathrm{ij}}=\min \left(\mathrm{m}_{\mathrm{mms}} / \mathrm{w}^{\mathrm{PR}}{ }_{\mathrm{kj}}\right)$ for all $\mathrm{P}_{\mathrm{k}} \in{ }^{\circ} \mathrm{T}_{\mathrm{j}}$.

Equation (10) means that for all transitions $T_{j}$, the ratios of average throughputs $x_{\text {atc } j} / x_{\text {ats } j}$ are identical and equal to the ratios of mean markings $m_{m m c} / m_{m m s}$ of the $T_{j}$ input places $P_{i}$ that drive the asymptotic behaviour of transitions $T_{j}$. This property will be used in next section to accelerate convergence.

Proof: For all transitions $T_{j}$, the asymptotic firing speed $x_{\text {atc }} j$ satisfies equation (2) and is given by:

$\mathrm{x}_{\text {atc } \mathrm{j}}=\left(\mathrm{w}_{\mathrm{ij}}^{\mathrm{PR}}\right) \cdot\left(\left(\mathrm{x}_{\text {ats j }}\right) /\left(\mathrm{m}_{\mathrm{mms}}\right)\right) \cdot \min \left(\mathrm{m}_{\mathrm{mmc} \mathrm{k}} / \mathrm{w}^{\mathrm{PR}}{ }_{\mathrm{kj}}\right)$

for all $P_{k} \in{ }^{\circ} T_{j}$. For join free CPN, the result is obvious: $x_{\text {atc }}$ $=\left(\mathrm{w}^{\mathrm{PR}}{ }_{\mathrm{ij}}\right) \cdot\left(\left(\mathrm{x}_{\text {ats j j }}\right) /\left(\mathrm{m}_{\mathrm{mms}}\right)\right) \cdot\left(\left(\mathrm{m}_{\mathrm{mmc}}\right) /\left(\mathrm{w}^{\mathrm{PR}}{ }_{\mathrm{ij}}\right)\right)=\left(\mathrm{x}_{\text {ats j }}\right) \cdot\left(\mathrm{m}_{\mathrm{mmc}}\right) /$ $\left(\mathrm{m}_{\mathrm{mms}}\right)=\alpha_{\mathrm{i}} \cdot \mathrm{x}_{\text {ats }} \mathrm{w}$ with $\mathrm{P}_{\mathrm{i}}={ }^{\circ} \mathrm{T}_{\mathrm{j}}$. Moreover the parameters $\alpha_{\mathrm{i}}$ are identical because the considered CPN is MTS. Equation (10) is obtained as a consequence.

For non join free but MTS CPN, all candidates for asymptotic firing speeds vector $X_{\text {atc }}$ will satisfy: $X_{\text {atc }}=\alpha$. $X_{\text {ats. }}$. As a consequence we have: $x_{\text {atc } j} / x_{\text {ats } j}=\min \left(m_{m m c k} / w^{P R}{ }_{k j}\right) \cdot\left(w^{P R}{ }_{i j}\right)$ $\left./\left(\mathrm{m}_{\mathrm{mms}}\right)\right)=\alpha$ for all $\mathrm{P}_{\mathrm{k}} \in{ }^{\circ} \mathrm{T}_{\mathrm{j}}$, and for all $\mathrm{j}=1, \ldots, \mathrm{q}$. A necessary condition to be satisfied by the mean markings of $\mathrm{CPN}$ is min $\left(\mathrm{m}_{\mathrm{mmck}} / \mathrm{w}^{\mathrm{PR}}{ }_{\mathrm{kj}}\right)=\min \left(\mathrm{m}_{\mathrm{mms} \mathrm{k}} / \mathrm{w}^{\mathrm{PR}}{ }_{\mathrm{kj}}\right)$ for all $\mathrm{P}_{\mathrm{k}} \in$ ${ }^{\circ} \mathrm{T}_{\mathrm{j}}$ and for all $\mathrm{j}=1, \ldots, \mathrm{q}$.

For the example described in Fig. 1, $\alpha=1$ : the steady state of the SPN can be obtained according to a CPN with maximal firing speed vector: $X_{\max }=(0.81,0.81,0.65,1,0.67)^{\mathrm{T}}$ (for example $\left.\mathrm{x}_{\max 5}=\mathrm{w}^{\mathrm{PR}}{ }_{95} \cdot\left(\mathrm{x}_{\text {ats }}\right) /\left(\mathrm{m}_{\mathrm{mms}} 9\right)=2.0 .5 / 1.48=0.67\right)$. Convergence of the CPN markings and throughputs is illustrated on Fig. 2 and Fig. 3, evolutions (solid lines) can be compared with SPN simulations (dashed lines). 
Throglpu torT5 CPN : solvillie, SPN : dxied Ihe, Markou model: dotte d llie)

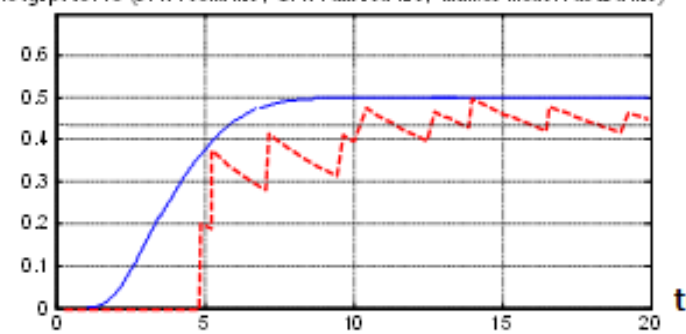

$t(s)$

Fig. 2. Throughput evolution Xate(t) and Xats(t) of CPN (solid line) and SPN (dashed line) in function of time, for example of Fig. 1.

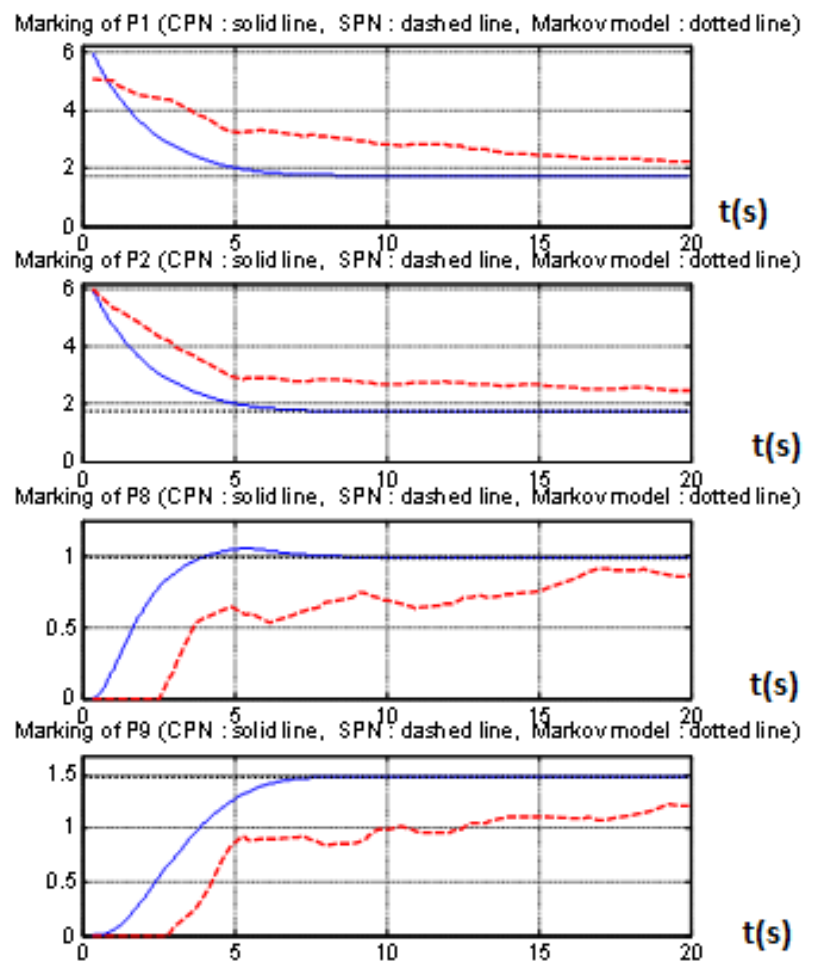

Fig.3. Markings evolution $M_{m m c}(t)$ and $M_{m m s}(t)$ of CPN (solid line) and SPN (dashed line) in function of time for example of Fig. 1.

\subsection{Convergence acceleration}

At a first glance, the use of $\mathrm{CPN}\left(\mathrm{X}_{\mathrm{ats}}, \mathrm{M}_{\mathrm{mms}}\right)$ seems to have a limited interest as long as the average throughputs and mean markings of the stochastic discrete model are required in order to work out $\mathrm{X}_{\max }$. But, the preceding result can be used in order to accelerate the convergence of stochastic simulations. The idea is to replace in equation (9) the exact average throughputs $X_{\text {ats }}$ and mean markings $M_{m m s}$ resulting from the analysis of the Markov model by their estimated values $\mathrm{X}_{\text {ats }}(\mathrm{T})$ and $\mathrm{M}_{\mathrm{mms}}(\mathrm{T})$ resulting from SPN simulation during a (short) time window of duration $\mathrm{T}$ and then to stop SPN simulation and to work out analytically the CPN steady state with an approximated maximal firing speed vector. The figures 4 and 5 depict the quadratic errors $E_{X}$ and $E_{M}$ with respect to $X_{\text {ats }}$ (i.e. $E_{X}=\left(X_{\text {ats }}-X_{\text {atc }}\right)^{\mathrm{T}} \cdot\left(X_{\text {ats }}-X_{\text {atc }}\right)$ ) and $M_{m m s}$ (i.e. $E_{M}=\left(M_{m m s}-M_{m m c}\right)^{T} .\left(M_{m m s}-M_{m m c}\right)$ ) worked out over the throughputs of all transitions and over the marking of all places. The errors obtained with CPN steady state calculation (solid lines) are nearly ever lower than the one obtained without CPN (dashed lines). In other words, the CPN steady state calculation can be used to accelerate the convergence of average throughputs and mean markings estimation. The gain in rapidity $\mathrm{g}_{\mathrm{r}}$ is about 2 to provide the same accuracy and the gain in precision $g_{p}$ is also about 2 for the same simulation duration.

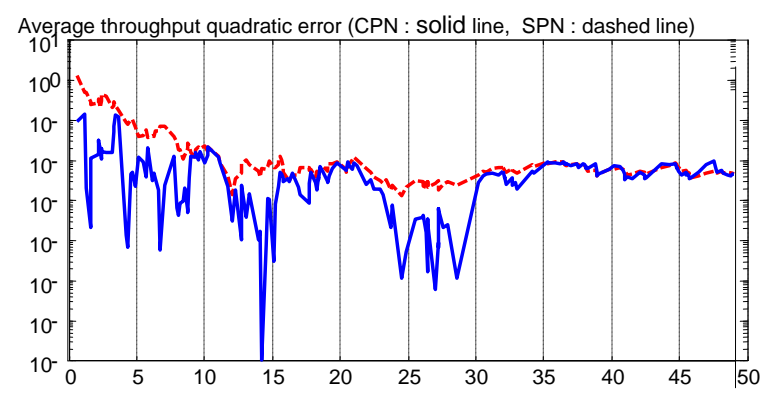

Fig. 4. Quadratic error on average throughputs for CPN (solid line) and SPN (dashed line) in function of time

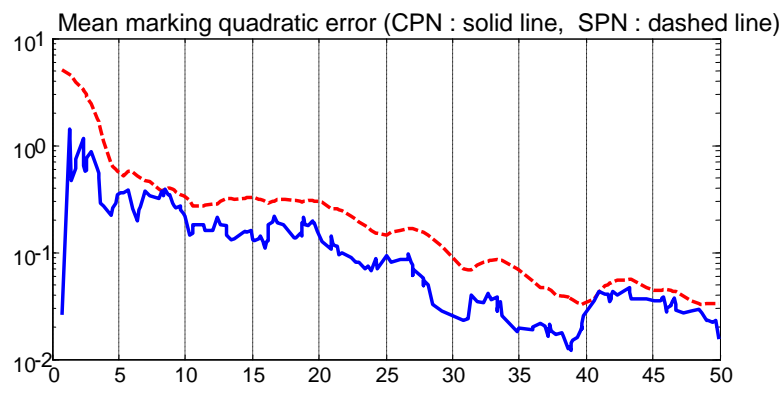

Fig. 5. Quadratic error on mean markings for CPN (solid line) and SPN (dashed line) in function of time.

\subsection{Firing speed adaptation}

When the steady state of SPN is unknown and cannot be estimated, the convergence acceleration described in section $V I . E$ is no more applicable. In that case, the maximal firing speed vector $\mathrm{X}_{\max }$ can be considered as a function of time and adapted with equation (11) in order to compensate the error on the firing speeds and markings:

$$
\dot{X}_{\text {max }}=\eta \cdot \operatorname{diag}(\mu) \cdot\left(\left(W^{T}\right) \cdot\left(M_{m m s}-M_{c}\right)+\left(X_{a t s}-X_{c}\right)\right)
$$

under the constraint $X_{\max } \geq 0$,where $\eta$ is the adaptation parameter arbitrary fixed to $0.1, \operatorname{diag}(\mu) \in\left(\mathrm{R}^{+}\right)^{\mathrm{q} \times \mathrm{q}}$ is the diagonal matrix with SPN firing rates.

Consider for example the SPN described in Fig.6 [4], [19]. This PN has $1 \mathrm{~T}$-semiflow $\mathrm{x}=\left(\begin{array}{llll}1 & 1 & 1 & 1\end{array}\right)^{\mathrm{T}}$ and $2 \mathrm{P}$-semiflows $\mathrm{y}_{1}$

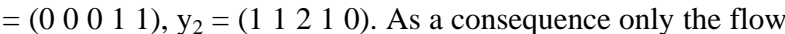
of transition $\mathrm{T}_{1}$ and the marking of places $\mathrm{P}_{1}, \mathrm{P}_{2}$ and $\mathrm{P}_{4}$ will be considered. The corresponding Markov model has 31 states and leads to steady state detailed in table 3 . In the same table are also reported the steady state obtained for CPN with $\mathrm{X}_{\max }$ $=\mu(\mathrm{CPN} 1)$ and with $X_{\max }$ given by equation (9) (CPN2).

Table 3. Average throughputs and mean markings of SPN and CPN from fig. 6.

\begin{tabular}{|c|c|c|c|c|}
\hline & $\mathbf{x}_{\text {at } 1}$ & $\mathbf{m}_{\text {at } 1}$ & $\mathbf{m}_{\text {at } 2}$ & $\mathbf{m}_{\text {at } \mathbf{~}}$ \\
\hline $\mathrm{SPN}$ & 0.80 & 1.03 & 0.80 & 3.01 \\
\hline $\mathrm{CPN} 1$ & 0.54 & 0.54 & 0.54 & 3.82 \\
\hline $\mathrm{CPN} 2$ & 1.33 & 1.70 & 1.33 & 1.70 \\
\hline
\end{tabular}




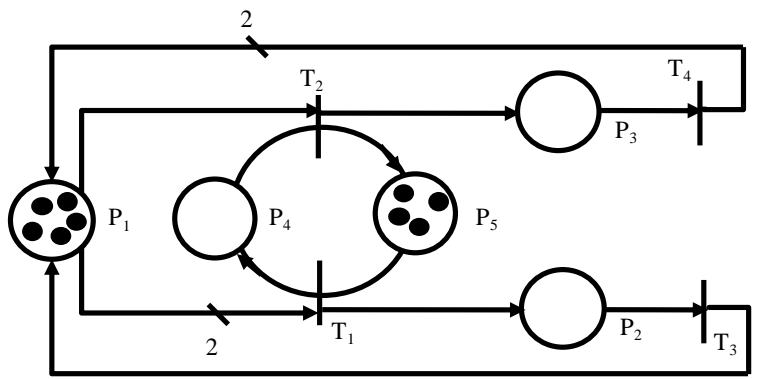

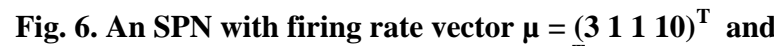
initial marking $M_{I}=\left(\begin{array}{lllll}5 & 0 & 0 & 0 & 4\end{array}\right)^{\mathrm{T}}\left[\begin{array}{ll}4 \\ \text { ) }\end{array}\right]$

One can notice that the average throughputs and mean markings of CPN2 verify the proportionality relations (10):

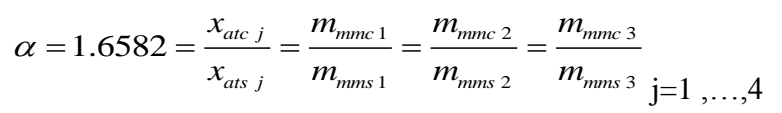

Let us notice that place $\mathrm{P}_{4}$ is not concerned in the previous relation because $\mathrm{m}_{\mathrm{mms} 4} / \mathrm{w}^{\mathrm{PR}}{ }_{42}>\mathrm{m}_{\mathrm{mms} 1} / \mathrm{w}^{\mathrm{PR}}{ }_{12}$. This relation is not verified in the case of CPN1. Marking and troughput evolutions are depicted in Fig 7 and 8.

Marking of P1 (CPN : solid line, SPN : dashed line, Markov model : dotted line)

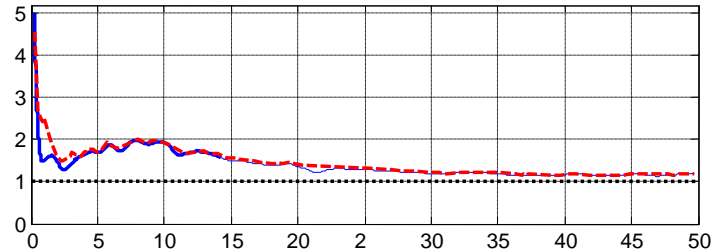

Marking of P2 (CPN : solid line, SPN : dashed line, Markov model : dotted line)

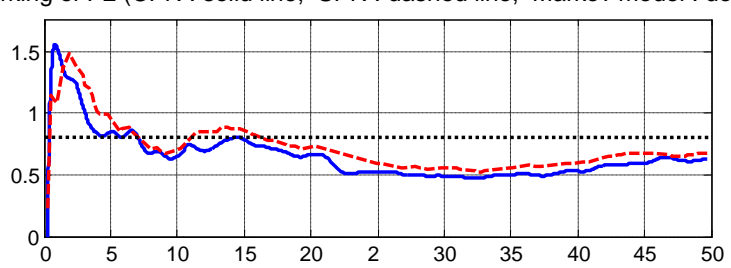

Marking of P4 (CPN : solid line, SPN : dashed line, Markov model : dotted line)

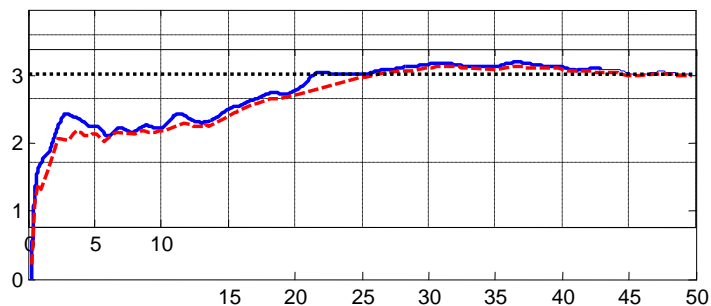

Fig. 7. Markings evolution of CPN (solid line) and SPN (dashed line) in function of time for example of Fig. 6.

An algorithm identical to the one proposed in section VI.D can be used to accelerate the convergence of the stochastic estimator of the average throughputs $X_{\text {ats }}$ and mean markings $\mathrm{M}_{\mathrm{mms}}$ of the Markov model. The adaptation parameter provided by equation (10) and depicted in Fig. 9 is worked out online with estimation $X_{\text {ats }}(T)$ and $M_{m m s}(T)$ of $X_{\text {ats }}$ and $M_{m m s}$. Then, SPN simulation is stopped and the CPN steady state is worked out. The Fig 10 and 11 depict the quadratic errors $\mathrm{E}_{\mathrm{X}}$ and $E_{M}$ with respect to $X_{\text {ats }}$ and $M_{m m s}$.
Throughput of T1 (CPN : solid line, SPN : dashed line, Markov model : dotted line)

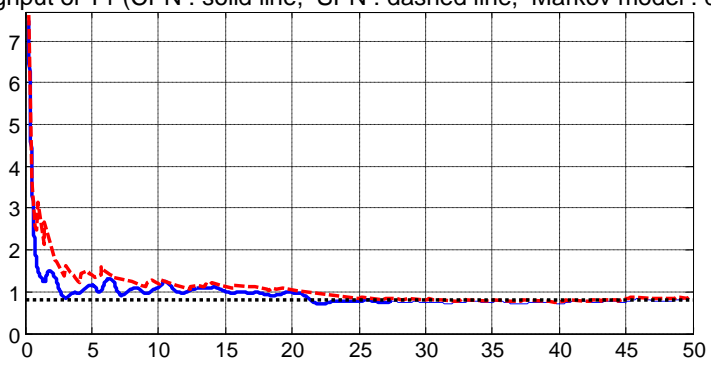

Fig. 8. Throughput evolution of CPN (solid line) and SPN (dashed line) in functionn of time for example of Fig. 6

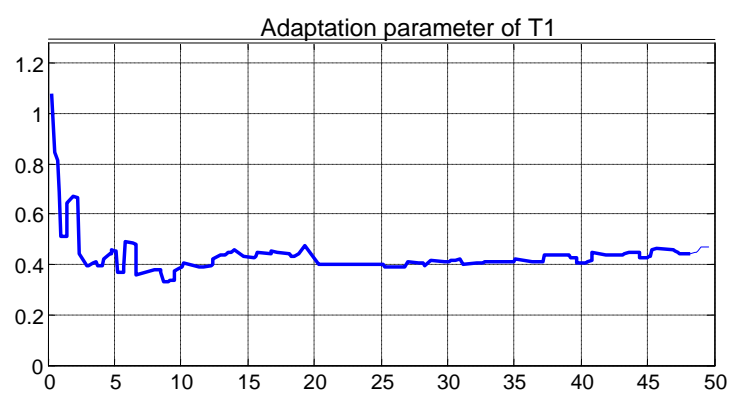

Fig. 9. Adaptation parameter $x_{\max } 1 / \mu_{1}$ for example of

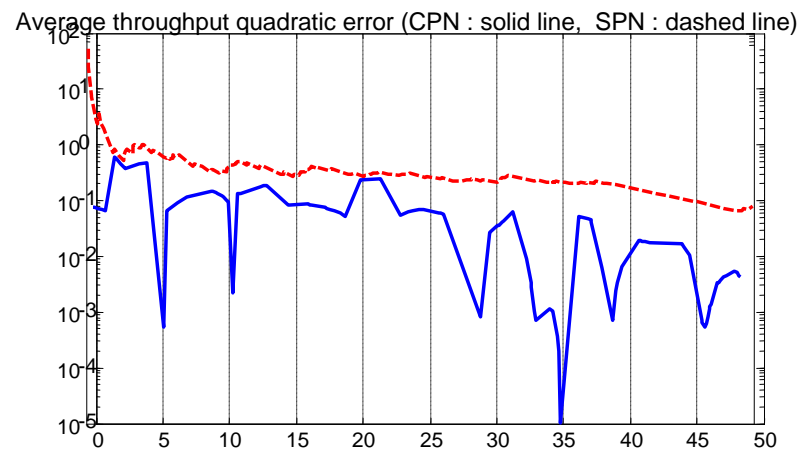

Fig. 10. Quadratic error EX for CPN (solid line) and SPN (dashed line) in function of time.

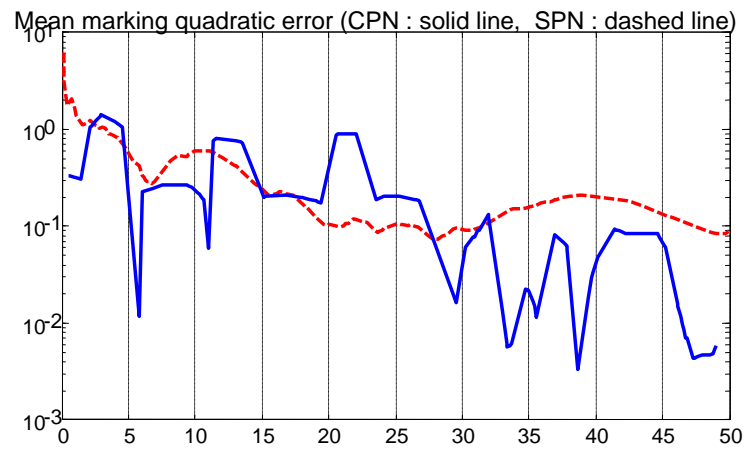

Fig. 11. Quadratic error $E_{M}$ for CPN (solid line) and SPN (dashed line) in function of time.

\section{CONCLUSIONS}

In this paper, MTS are considered because this kind of PN have been proved to have a unique parameter $\alpha$. Then the convergence of SPN to steady state has been accelerated thanks to CPN. The maximal firing speed vector of CPN has been defined according to the SPN average throughputs and 
mean markings. As long as these values are unknown, the exact values are estimated thanks to a SPN simulation over a short time interval. Two solutions are investigated. The first solution is to define the maximal firing speeds as constant values and the second one is to define these speeds as time varying parameters. Both solutions can be used for convergence acceleration. In our future works, we will continue our investigation about SPN steady state approximation by means of CPN.

The future work is to investigate continuous approximations directly derived from the SPNs transition firing rates.

\section{REFERENCES}

[1] M. Ajmone Marsan, G. Chiola, On Petri nets with deterministic and exponentially distributed firing times, Advances in Petri nets (Rozenberg G.), Springer Verlag, (1987) pp. 132-145.

[2] M.K. Molloy, Performance analysis using stochastic Petri nets, IEEE Tran. Comp. C, 31, (1982) pp. 913 - 917.

[3] R. David, H. Alla, Petri nets and grafcet - tools for modelling discrete events systems, Prentice Hall, London (1992).

[4] J. Julvez, L. Recalde, M. Silva, Steady-state performance evaluation of continuous mono-T-semiflow Petri nets, Automatica, 41 (4), (2005) pp. 605-616.

[5] M. Rausand, A. Hoyland, System reliability theory: models, statistical methods, and applications, Wiley, Hoboken, New Jersey, (2004).

[6] Zaitsev, Dmitry (2013). Clans of Petri Nets: Verification of protocols and performance evaluation of networks. LAP LAMBERT Academic Publishing. ISBN 978-3-65942228-7.

[7] Vazquez R., Silva M., Hybrid approximations of markovian Petri nets, Proc. IFAC Conference on Analysis and Design of hybrid Systems, (2009) Zaragoza, Spain.

[8] Kara R., Loiseau J.J., Djennoune S. (2008) Quantitative analysis of continuous weighted marked graphs, Nonlinear Analysis: Hybrid Systems, Vol. 2, pp. 10101020 .

[9] Mahulea C., Ramirez Trevino A., Recalde L., Silva M.,
(2008), Steady state control reference and token conservation laws in continuous Petri nets, Trans. IEEE TASE, Vol. 5, no. 2, pp. $307-320$.

[10] Bobbio, A. Puliafito, M. Telek, K. Trivedi, Recent Developments in Stochastic Petri Nets, J. of Cir., Syst., and Comp., 8 (1), (1998) pp. 119-158.

[11] L. Recalde, E. Teruel, M. Silva, Autonomous continuous $\mathrm{P} / \mathrm{T}$ systems, Lecture notes in computer science, vol. 1639, (1999) pp 107 - 126.

[12] D. Lefebvre, E. Leclercq, N. El Akchioui, L. Khalij, E. Souza de Cursi, A geometric approach for the homothetic approximation of stochastic Petri nets, Proc. IFAC WODES, (2010) Berlin, Germany.

[13] Diaz M., (2001) Les réseaux de Petri : modèles fondamentaux, Hermes, Paris.

[14] R. Vazquez, L. Recalde, M. Silva, Stochastic continuousstate approximation of markovian Petri net systems, Proc. IEEE - CDC08, (2008) pp. 901 - 906, Cancun, Mexico.

[15] L. Recalde, M. Silva, Petri nets and integrality relaxations: a view of continuous Petri nets, Trans. IEEE - SMC, part C, 32(4), (2002) pp. 314-326.

[16] D. Lefebvre, About the stochastic and continuous Petri nets equivalence in long run, Non-Linear Analysis, Hybrid Systems (NAHS), vol.5, pp. 394-406, 2011.

[17] Mahulea C., Giua A., Recalde L., Seatzu C., Silva M., (2006), On sampling continuous timed Petri nets: reachability "equivalence" under infinite servers semantics, Proceeding IFAC - ADHS, pp. 37 - 43. Alghero, Italy.

[18] Demongodin I., Giua A., (2002) Some time analysis methods for continuous and hybrid Petri nets, IFAC World Congress, Barcelona, Spain.

[19] D. Lefebvre, E. Leclercq, L. Khalij, E. Souza de Cursi, N. El Akchioui, Approximation of MTS stochastic Petri nets steady state by means of continuous Petri nets: a numerical approach, Proc. IFAC ADHS, (2009) pp. 6267, Zaragoza, Spain.

[20] L. Recalde, M. Silva, On fluidification of Petri Nets: from discrete to hybrid and continuous models, An. Reviews in Control, 28(2), (2004) pp. 253-266. 